\title{
Atención de la epilepsia de clase mundial en el corazón de México
}

\section{World class epilepsy care in the heart of Mexico}

Imad M Najm*

Citar como: Najm IM. Atención de la epilepsia de clase mundial en el corazón de México. An Med (Mex). 2020; 65 (3): 172-173. https://dx.doi.org/10.35366/95672

La Organización Mundial de la Salud reconoce la epilepsia como un grave problema de salud pública con más de 50 millones de personas que la padecen en todo el mundo. Un informe reciente de los Centros para el Control y la Prevención de Enfermedades en los Estados Unidos estimó recientemente que hasta $56 \%$ de los adultos con epilepsia en ese país tienen convulsiones no controladas. ${ }^{1}$ La cirugía de epilepsia se ha convertido en una excelente opción en niños y adultos con epilepsia farmacorresistente. Para un subgrupo cuidadosamente seleccionado de pacientes con epilepsia focal farmacorresistente se ha demostrado que la resección quirúrgica es una opción de tratamiento más eficaz que la terapia farmacológica continua. ${ }^{2} \mathrm{Re}-$ cientemente se ha calculado una prevalencia de $\sim 50$ candidatos para cirugía de epilepsia de cada 100,000 adultos y de $\sim 15$ de cada 100,000 niños y una incidencia anual de tres candidatos para cirugía de epilepsia de cada 100,000 adultos y dos de cada 100,000 niños (López-Rivera y colaboradores [en prensa]).

Este número especial de Anales Médicos es una revisión oportuna del estado actual de la atención de la epilepsia en México y América Latina. De acuerdo con este número, la epilepsia es más prevalente en México y América Latina en comparación con los

* Director del Centro de Epilepsia. Cleveland Clinic Foundation.

Recibido para publicación: 10/08/2020. Aceptado: 19/08/2020.

Correspondencia: Imad M Najm

Clínica de Epilepsia, Cleveland Clinic Foundation. Cleveland, OH, EUA.

E-mail: najmi@ccf.org
Estados Unidos, con una prevalencia estimada entre 3.9 y 42.2 por cada 1,000 habitantes en México.

El éxito de la cirugía de epilepsia depende de cuatro pilares interconectados e interdependientes: 1 ) un enfoque de equipo multidisciplinario, 2) tecnologías de vanguardia, 3) innovación y 4) resultados medibles. Debemos asegurarnos de que no haya ningún punto débil en un programa de cirugía de epilepsia, lo que evitará poner en riesgo su efectividad.

Los artículos fundamentales de esta revisión muestran el papel de liderazgo que el Centro de Epilepsia del Hospital ABC ha asumido recientemente en la cirugía de epilepsia en México. El Hospital $\mathrm{ABC}$ ha logrado construir un verdadero enfoque multidisciplinario con neurólogos, neurofisiólogos, neurocirujanos, neurorradiólogos, neuropsicólogos y especialistas en bioética que trabajan juntos para atender a pacientes con epilepsia de todas las edades. El equipo del Centro Médico ABC destaca el papel de la electroencefalografía, las imágenes estructurales y funcionales de alta definición así como la evaluación neuropsicológica que influyen de manera positiva en los resultados quirúrgicos. En respuesta a la pandemia actual la electroencefalografía se ha utilizado para el tratamiento de pacientes con COVID-19.

Uno de los principales indicadores de un programa maduro e integral de cirugía de epilepsia es la presencia de un equipo de bioética. El manuscrito adjunto sobre bioética y epilepsia lo ilustra adecuadamente.

Varios de los manuscritos y revisiones de este número destacan la contribución de la tecnología de punta en el éxito de la cirugía de epilepsia. La innovación representa un punto fundamental para el éxi- 
to continuo y el futuro de todo programa de epilepsia como lo señala el informe de Font-Réaulx y colaboradores del Centro de Epilepsia ABC. En este informe los autores presentan un enfoque innovador para la medición in situ de la temperatura cortical y su correlación con la cronicidad de la epilepsia. Este método tiene potencial más allá de la simple medición de la temperatura cortical, ya que posiblemente servirá como una importante herramienta intraoperatoria para la localización y la definición de la extensión de la zona epileptogénica.

Por último, pero no menos importante, la mejor validación del éxito de todo programa de cirugía de epilepsia es el informe de los resultados sobre el control de convulsiones. Los resultados del programa $\mathrm{ABC}$ reportados en este número están por encima del promedio nacional e internacional en una población de pacientes niños y adultos.
Como viejo amigo de muchos colegas, involucrados en la atención de pacientes con epilepsia en México, he tenido el privilegio personal y el honor de ser un testigo cercano de esta transformación desde la inauguración del campus del Hospital ABC en Santa Fe en octubre de 2004. Ésta ha sido una experiencia personalmente gratificante, pero el mayor beneficio ha sido para los pacientes de todas las edades que sufren de epilepsia en México y Centroamérica.

\section{BIBLIOGRAFÍA}

1. Tian N, Boring M, Kobau R, Zack MM, Croft JB. Active epilepsy and seizure control in adults - United States, 2013 and 2015. MMWR Morb Mortal Wkly Rep. 2018; 67 (15): 437-442.

2. Wiebe S, Blume WT, Girvin JP, Eliasziw M; Effectiveness and Efficiency of Surgery for Temporal Lobe Epilepsy Study Group. A randomized, controlled trial of surgery for temporallobe epilepsy. N Engl J Med. 2001; 345 (5): 311-318. doi: 10.1056/NEJM200108023450501. 